The Journal of Clinical Investigation

Vol. 46, No. 12, 1967

\title{
Tyrosine Metabolism in Patients with Liver Disease*
}

\author{
Robert J. Levine and Harold O. Conn \\ (From the Departments of Medicine and Pharmacology, Yale University School of Medicine, \\ New Haven, Connecticut, and the Veterans Administration Hospital, \\ West Haven, Connecticut)
}

\begin{abstract}
Plasma levels of tyrosine were assayed in the fasting state and after oral administration of either tyrosine (tyrosine tolerance test) or phenylalanine (phenlyalanine conversion test) in normal subjects and in patients with hepatitis, biliary obstruction, or cirrhosis. Fasting tyrosine levels tended to be slightly increased in patients with hepatitis and biliary obstruction and markedly increased in patients with cirrhosis.

Tyrosine tolerance tests in patients with cirrhosis were characterized by larger than normal increments in tyrosine levels and by delayed returns toward fasting levels.

The results of phenylalanine conversion tests were abnormal in approximately one-half of patients with either hepatitis or biliary obstruction and four-fifths of patients with cirrhosis. Abnormalities were characterized by elevated fasting plasma tyrosine levels, or small and delayed increments in tyrosine levels, or both. Abnormal phenylalanine conversion test results in patients with cirrhosis did not correlate closely with any clinical feature of cirrhosis or with the results of any standard liver function test; there was positive correlation only with abnormal ammonia tolerance, a test of portalsystemic shunting. Tests of tyrosine metabolism do not appear to be useful for routine clinical assessment of liver function. Tyrosine tolerance tests and phenylalanine conversion tests done for purposes of diagnosis of other diseases may yield misleading results in patients with liver disease.
\end{abstract}

\section{Introduction}

Tyrosine is an aromatic amino acid that serves as a precursor for a variety of biologically important substances; e.g., catecholamines, thyroid hormones, melanin pigments, and protein. Mammals may obtain tyrosine from either of two sources. It is ingested in foods either as the free amino acid or as a component of dietary proteins;

\footnotetext{
* Received for publication 19 May 1967 and in revised form 26 July 1967.

A partial account of this work was published in abstract form in Clin. Res. 1965. 13: 372.

This work was supported by grants from the Veterans Administration, the National Institute of Health (CA08341), the Erwin Strasburger Memorial Medical Foundation, and the Stratfield Fund.

Address requests for reprints to Dr. Robert J. Levine, Department of Medicine, Yale University School of Medicine, 333 Cedar Street, New Haven, Conn. 06510.
}

it may also be synthesized from phenylalanine. The two major mechanisms for removal of tyrosine from the body are urinary excretion and catabolic degradation to $p$-hydroxyphenylpyruvic acid; the latter process is catalyzed by the enzyme, Ltyrosine: 2-oxyglutarate aminotransferase (EC 2.6.1.5) (tyrosine transaminase).

Tyrosine transaminase is concentrated in the liver (1). It has been known for over $100 \mathrm{yr}$ that tyrosine metabolism is abnormal in patients with liver disease. The first suggestion of this abnormality has been attributed to Frerichs who, in 1854 , reported the presence of tyrosine and leucine crystals in the urine of patients with acute yellow atrophy (2). In 1943, Bernhart and Schneider, using a nonspecific colorimetric method, studied plasma tyrosine levels in patients with liver disease (3). They reported that fasting levels of 
tyrosine tended to be high in these patients. Furthermore, after oral administration of tyrosine, elevations in plasma tyrosine levels tended to be greater than were seen in patients without liver disease. They suggested that the tyrosine tolerance test could serve as a useful test of liver function.

The tyrosine tolerance test, however, failed to gain widespread use in the diagnosis of liver disease as it offered no particular advantage over other, more convenient liver function tests. Furthermore, it did not prove to be specific for liver disease; high plasma tyrosine levels or abnormal tyrosine tolerance tests have been detected in several other conditions; e.g., in patients with tyrosinosis (4), thyrotoxicosis (5-7), scurvy (6, $7)$, or renal failure (6), and in association with anticoagulant therapy (6).

The metabolic conversion of phenylalanine to tyrosine is catalyzed by the enzyme, phenylalanine 4-hydroxylase (EC 1.14.3.1) (8). This reaction has not been found to occur, to any significant extent, in any mammalian tissues other than liver and neoplastic murine mast cells (9). Apparently, reduced conversion of phenylalanine to tyrosine has been reported previously only in two conditions. Patients with phenylketonuria have congenital absence of phenylalanine hydroxylase (10); in some heterozygous carriers of this disease, partial deficiencies in the enzyme may be demonstrated by reduced conversion of phenylalanine to tyrosine (11-13). Impaired tyrosine synthesis has been reported also in patients treated with folic acid antagonists such as amethopterin (14); the cofactor for phenylalanine hydroxylase is a reduced pteridine (8).

This paper reports the results of studies on the metabolism of tyrosine in patients with various types of liver disease; tyrosine levels in plasma were assayed by a specific fluorometric method. Patients with liver disease tended to have high fasting plasma tyrosine levels and abnormal tyrosine tolerance tests. There was subnormal conversion of phenylalanine to tyrosine in patients with biliary obstruction as well as primary hepatocellular disease. The impairment of phenylalanine conversion correlated positively with abnormal ammonia tolerance tests but not with the results of other standard liver function tests.

\section{Methods}

Tyrosine assay. Venous blood was aspirated into 10 $\mathrm{ml}$ heparinized Vacutainer tubes (Becton, Dickinson \& Co., Rutherford, N. J.). After centrifugation, plasma was removed and stored at $-20^{\circ} \mathrm{C}$ until assayed. Tyrosine in plasma was assayed by a modification of the method of Waalkes and Udenfriend (15). Modification was necessary because, at high levels of tyrosine, fluorescence was not a linear function of tyrosine concentration. Assays were done on $0.5 \mathrm{ml}$ rather than on $1.0 \mathrm{ml}$ samples of plasma. When the fluorescence of any sample was found to exceed the range of linearity, it was diluted with a sufficient volume of reagent blank to lower its reading into the linear range.

Amino acid loading procedures. Subjects fasted for 12 $\mathrm{hr}$ before ingesting the amino acids. The tyrosine tolerance test consisted of feeding the subject L-tyrosine (50 $\mathrm{mg} / \mathrm{kg}$ body weight) mixed thoroughly in applesauce; blood samples were obtained before, and at $60,120,240$, and $360 \mathrm{~min}$ after tyrosine feeding. The phenylalanine conversion test consisted of feeding L-phenylalanine (100 $\mathrm{mg} / \mathrm{kg}$ body weight) mixed thoroughly in applesauce; blood samples were obtained before, and at $30,60,120$, and $240 \mathrm{~min}$ after phenylalanine feeding. L-tyrosine and L-phenylalanine were purchased from Nutritional Biochemicals Corporation, Cleveland, Ohio.

Subjects for study. Amino acid loading tests were done on 10 normal subjects, from 20 to $40 \mathrm{yr}$ of age and $58 \mathrm{pa}-$ tients, aged 18-70 yr, with liver disease. All patients had been admitted to either the Veterans Administration Hospital or the Yale-New Haven Medical Center between 1 January 1965 and 1 May 1966. 13 patients had hepatitis; in 10 the diagnosis was confirmed histologically. 12 were thought to have viral hepatitis; 1 was attributed to ethionamide toxicity. 12 patients had biliary obstruction; of these, 6 were caused by neoplasm, 4 by gallstone, 1 by stricture, and 1 was associated with pancreatitis. 24 patients had cirrhosis; in each case this diagnosis was documented histologically; 23 had Laennec's cirrhosis and 1 had hemochromatosis. 9 additional cirrhotic patients with portacaval anastamoses were studied. In 5 patients phenylalanine conversion tests were done both before and after portacaval anastamosis.

Liver function tests including serum bilirubin, bromsulphalein retention (BSP), thymol turbidity, alkaline phosphatase, serum glutamic-oxalacetic transaminase (SGOT), serum albumin, and ammonia tolerance tests (16) were done by standard techniques. The presence and magnitude or absence of jaundice, spider angiomata, hepatomegaly, splenomegaly, and ascites were recorded at the time of investigation. Cirrhotic patients were examined for the presence or absence of esophageal varices by an experienced observer who used an Eder-Hufford esophagoscope.

\section{Results}

Plasma tyrosine levels in fasting patients. In 15 normal subjects fasting plasma tyrosine levels varied from 9 to $19 \mu \mathrm{g} / \mathrm{ml}$ (mean $12.7 \pm 3.0, \mathrm{sD}$ ). 
These levels are similar to values reported previously for normal subjects $(5,6)$.

Fasting plasma tyrosine levels were determined in 150 consecutive patients with diverse diseases who reported to the clinical chemistry laboratory for blood withdrawal. Of these, 21 had known liver disease, and 2 had treated thyrotoxicosis. In the 127 patients without known disease of liver or thyroid, fasting tyrosine levels varied from 7.8 to $19.6 \mu \mathrm{g} / \mathrm{ml}$ (mean, $12.5 \pm 2.7$ ). Of the entire group of 150 patients, 9 had fasting tyrosine levels above $19 \mu \mathrm{g} / \mathrm{ml}$; of these, 7 had overt liver disease. One $73 \mathrm{yr}$ old man with no known disease other than lenticular cataracts had a level of 19.6 $\mu \mathrm{g} / \mathrm{ml}$. A level of $19.6 \mu \mathrm{g} / \mathrm{ml}$ was found in a 58 yr old man with aseptic necrosis of the hip. The possibility that they were not truly fasting could not be excluded. Thus, the incidence of high fasting tyrosine levels that could not be explained by known causes was less than $2 \%$.

Fasting plasma tyrosine levels were determined on more than 1 day in each of 24 patients. Differences in values obtained ranged from 0 to 16 $\mu \mathrm{g} / \mathrm{ml}$ and averaged $2.0 \mu \mathrm{g} / \mathrm{ml}$ in normal subjects and $3.0 \mu \mathrm{g} / \mathrm{ml}$ in cirrhotic patients. The $16 \mu \mathrm{g} / \mathrm{ml}$ difference was found in a cirrhotic patient whose determinations yielded values of 36,50 , and 52 $\mu \mathrm{g} / \mathrm{ml}$ on 3 different days.

Fasting plasma tyrosine levels from all patients to whom amino acid loading tests were administered are compiled in Fig. 1. Mean levels in patients with either hepatitis or biliary obstruction were slightly higher than in normal patients. In patients with cirrhosis, mean tyrosine levels were elevated significantly above normal.

Tyrosine tolerance tests. In normal subjects, tyrosine tolerance tests were characterized by a sharp rise in plasma tyrosine levels; mean maximum levels occurred at $60 \mathrm{~min}$ and levels had decreased substantially by $240 \mathrm{~min}$ (Table I). These results are similar to previously reported normal values (6).

In cirrhotic patients, fasting tyrosine levels were elevated; mean peak levels were observed at $120 \mathrm{~min}$. Although peak levels were higher in cirrhotic patients than in normal subjects, the most characteristic abnormality was delayed return of tyrosine levels toward fasting levels (Table I).

Phenylalanine conversion tests. Phenylalanine conversion tests in normal subjects were characterized by a prompt rise from fasting tyrosine

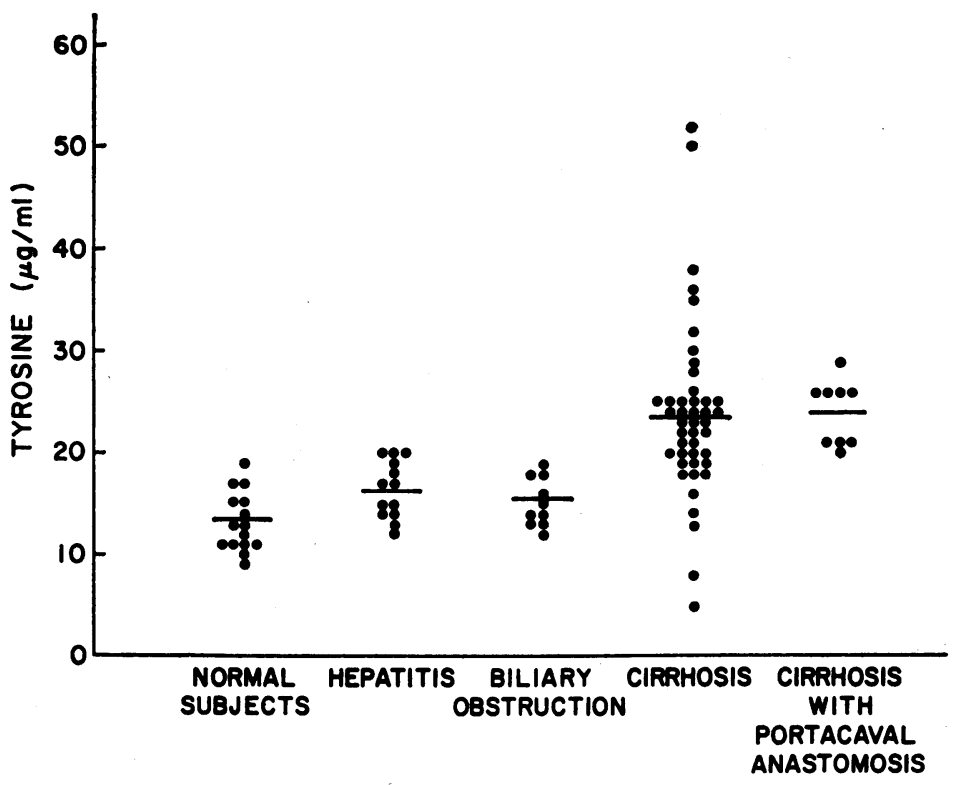

Fig. 1. Fasting plasma tyrosine levels in NORMal subjects and IN PATIENTS WITH VARIOUS TYPES OF LIVER DISEASE. Each point represents a single determination. The horizontal line indicates the mean for each group. 
TABLE I

Tyrosine tolerance tests*

\begin{tabular}{|c|c|c|c|c|c|c|}
\hline \multirow[b]{2}{*}{ Subjects } & \multirow[b]{2}{*}{ No. } & \multirow[b]{2}{*}{ Time: $\min 0$} & \multicolumn{3}{|c|}{ Plasma tyrosine concentrations } & \multirow[b]{2}{*}{360} \\
\hline & & & 60 & 120 & 240 & \\
\hline $\begin{array}{l}\text { Normal } \\
\text { Laennec's cirrhosis }\end{array}$ & $\begin{array}{l}5 \\
9\end{array}$ & $\begin{array}{l}14.0 \pm 2.2 \\
24.7 \pm 7.6\end{array}$ & $\begin{array}{l}64.8 \pm 14.3 \\
76.7 \pm 21.5\end{array}$ & $\begin{array}{l}59.4 \pm 5.3 \\
80.2 \pm 11.6\end{array}$ & $\begin{array}{l}29.0 \pm 3.2 \\
70.0 \pm 15.6\end{array}$ & $\begin{array}{l}24.0 \pm 3.5 \\
58.4 \pm 13.0\end{array}$ \\
\hline
\end{tabular}

* Plasma tyrosine levels $(\mu \mathrm{g} / \mathrm{ml}$, mean $\pm \mathrm{SD})$ before and at various times after oral administration of tyrosine, $50 \mathrm{mg} / \mathrm{kg}$ body weight.

levels to a mean peak of $26.8 \mu \mathrm{g} / \mathrm{ml}$ at $3 \mathrm{hr}$ (Table II, Fig. 2). These findings are similar to those reported previously in normal subjects (11, $13,14)$. Increments in plasma tyrosine levels ranged from 7 to $20 \mu \mathrm{g} / \mathrm{ml}$ (mean, 15.7). In 8 of the 10 subjects the peak tyrosine level was more than twice the fasting concentration, and the mean peak level was $217 \%$ of the fasting tyrosine concentration (Fig. 1). In 1 subject, whose fasting level was $19 \mu \mathrm{g} / \mathrm{ml}$, an increase of only $7 \mu \mathrm{g} / \mathrm{ml}$ was observed. The explanation for the relatively high fasting level is not known.

The shape of the individual curves of plasma tyrosine concentrations varied considerably (Fig. 3 ). In two subjects the peak occurred at $1 \mathrm{hr}$, in three at $2 \mathrm{hr}$, in two at $3 \mathrm{hr}$, and in three at $4 \mathrm{hr}$.

For purposes of subsequent discussion we shall define a normal phenylalanine conversion test as one in which the fasting plasma tyrosine level is no greater than $19 \mu \mathrm{g} / \mathrm{ml}$ and the peak increment is no less than $7 \mu \mathrm{g} / \mathrm{ml}$.

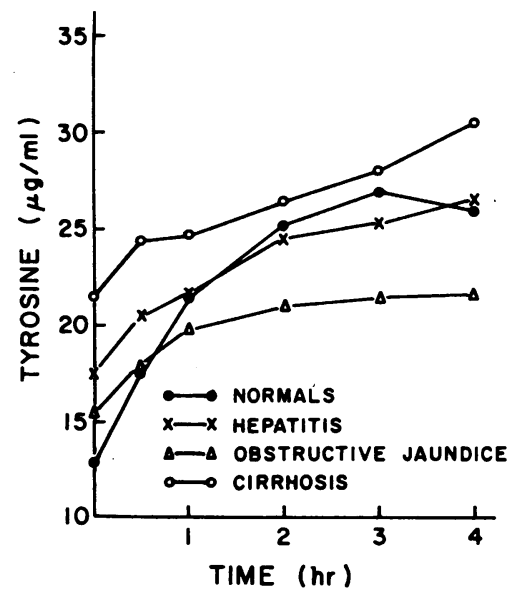

Viral hepatitis. Although the mean fasting plasma tyrosine concentration was higher in patients with hepatitis than in normal subjects, the increase in tyrosine levels after phenylalanine administration was smaller and more gradual (Fig. 2 , Table II). Increments in plasma tyrosine concentrations ranged from 5 to $17 \mu \mathrm{g} / \mathrm{ml}$ (mean, 11.1). In only 2 of the 13 subjects was the peak tyrosine level at least twice the fasting concentration. The mean tyrosine peak was $164 \%$ of fasting tyrosine level. The peak tyrosine concentration was not reached by $1 \mathrm{hr}$ in any of the 13 patients. In five patients the peak was observed at $2 \mathrm{hr}$, in four at $3 \mathrm{hr}$, and in four at $4 \mathrm{hr}$. Plotted as per cent of fasting tyrosine levels the curves in patients with hepatitis differed clearly from those of normal subjects (Fig. 2).

The results of the phenylalanine conversion tests were normal in seven patients with hepatitis. In four patients abnormally flat patterns with increments less than $7 \mu \mathrm{g} / \mathrm{ml}$ were seen. In two

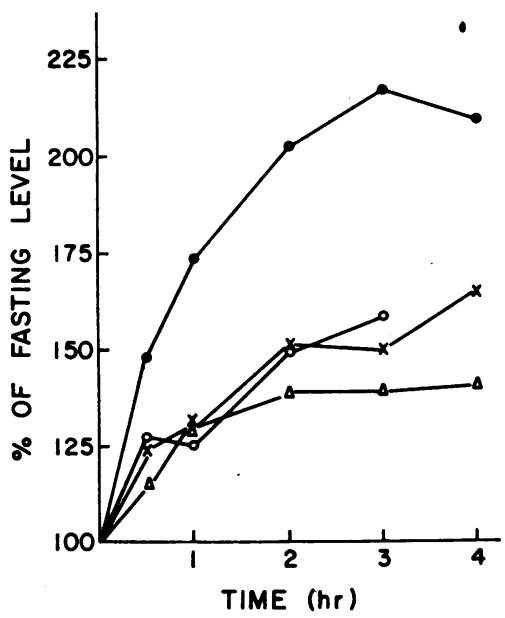

Fig. 2. Mean phenylalanine conversion test results in NORMal subJECTS AND IN PATIENTS WITH VARIOUS TYPES OF LIVER DISEASE EXPRESSED AS ACTUAL PLASMa tYRosine leVELS IN $\mu \mathrm{g} / \mathrm{ml}$ (LEFT) AND AS PER CENT OF FASTING LEVEL OF TYROSINE (RIGHT). 
TABLE II

Phenylalanine conversion tests*

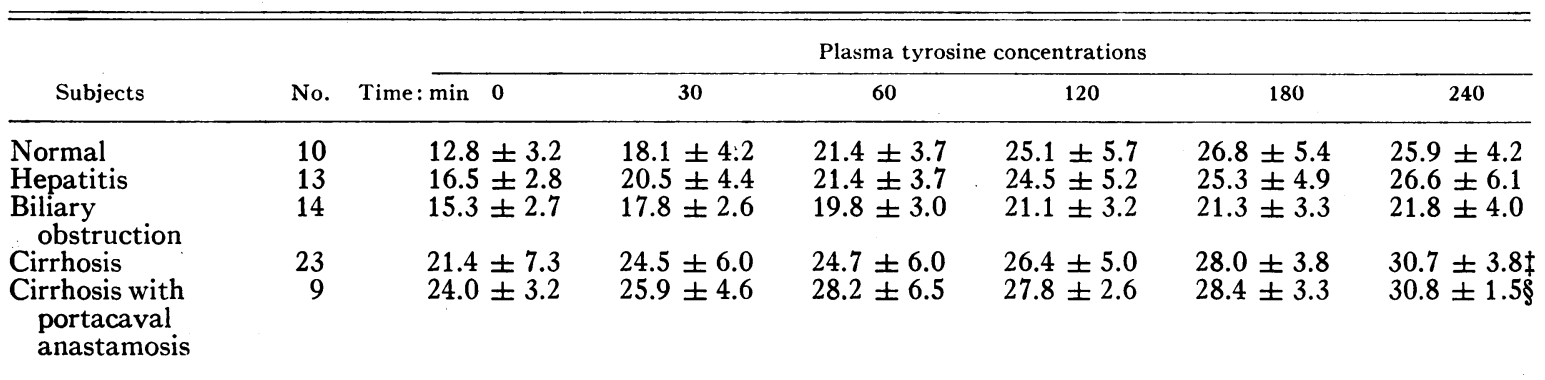

* Plasma tyrosine levels $(\mu \mathrm{g} / \mathrm{ml}$, mean $\pm \mathrm{SD})$ before and at various times after oral administration of phenylalanine, $100 \mathrm{mg} / \mathrm{kg}$ body weight.

$\ddagger 13$ patients.

$\S 6$ patients.

others there were abnormally elevated fasting levels associated with normal increments in tyrosine concentration. Mean serum bilirubin levels and SGOT activities were higher in patients with abnormal phenylalanine conversion tests than in those with normal tests; however, the differences were not statistically significant. Two of three patients with subacute hepatic necrosis demonstrated histologically had normal phenylalanine conversion tests.

In two patients phenylalanine conversion tests were repeated after clinical improvement had occurred (Table III). One patient (K. B.), whose initial test was abnormally flat, had a normal test

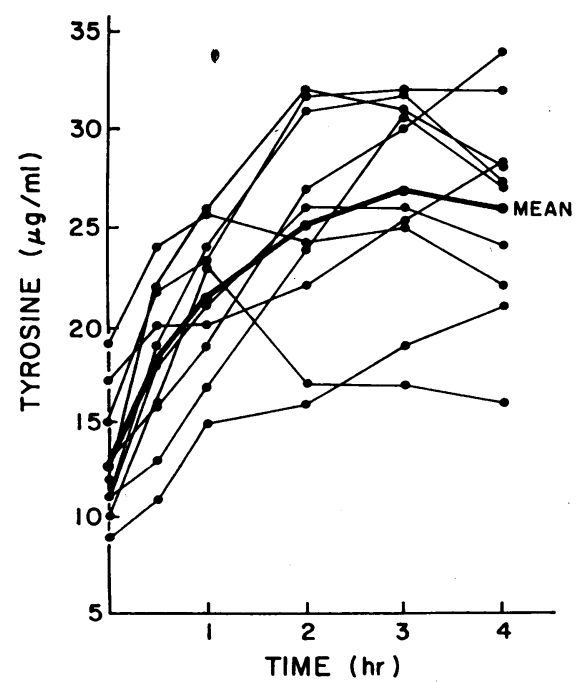

Fig. 3. Phenylalanine conversion test curves in NORMAL INDIVIDUALS. Mean results are indicated by the heavy line.
4 months later after complete recovery. The other patient (H. McD.) exhibited a borderline test on the 25th day of a mild hepatitis; 10 days later the test was normal.

Obstrucitve jaundice. Phenylalanine conversion tests in patients with obstructive jaundice were characterized by high-normal fasting tyrosine levels and by small, gradual increases in plasma tyrosine concentrations (Table II, Fig. 2). Increments in plasma tyrosine levels ranged from 5 to 14 (mean, $7.8 \mu \mathrm{g} / \mathrm{ml}$ ). Maximal tyrosine levels were reached in one patient at $1 \mathrm{hr}$, in six patients at $2 \mathrm{hr}$, in two patients at $3 \mathrm{hr}$, and in three patients at $4 \mathrm{hr}$. The mean peak tyrosine level averaged $142 \%$ of the fasting tyrosine concentrations (Fig. 2). In none of the 12 patients did the tyrosine concentration double the fasting level.

In six patients with obstructive jaundice there were abnormally flat curves with increments less than $7 \mu \mathrm{g} / \mathrm{ml}$; in six patients the curves were normal. Results of phenylalanine conversion tests did not correlate significantly with either the cause of the biliary obstruction or the degree of abnormality of any liver function test.

Phenylalanine conversion tests were repeated in two patients with abnormal tests after surgical relief of obstructive jaundice (Table III). In one patient (S. S.) the test became normal within 3 wk of surgery despite the presence of hepatic metastases. The other patient (A. S.) underwent choledocholithotomy without complication with complete return to normal of the results of liver function tests; the phenylalanine conversion test 
TABLE III

Serial Phenylalanine Conversion Tests

\begin{tabular}{|c|c|c|c|c|c|c|c|c|c|}
\hline \multirow[b]{2}{*}{ Patient } & \multirow[b]{2}{*}{ Diagnosis } & \multirow[b]{2}{*}{ Date } & \multirow[b]{2}{*}{ Time: $\min$} & \multicolumn{6}{|c|}{ Plasma tyrosine concentrations } \\
\hline & & & & 0 & 30 & 60 & 120 & 180 & 240 \\
\hline \multirow[t]{2}{*}{ K.B. } & Viral hepatitis, active & $2 / 13 / 65$ & & 15 & 20 & 20 & 22 & 22 & 21 \\
\hline & Recovered & $6 / 8 / 65$ & & 14 & 21 & 23 & 25 & 23 & 24 \\
\hline \multirow[t]{2}{*}{ H.McD. } & Viral hepatitis, mild & $1 / 9 / 65$ & & 15 & 19 & 19 & 20 & 23 & 24 \\
\hline & Viral hepatitis, subsiding & $1 / 19 / 65$ & & 16 & 22 & 23 & 26 & 25 & 25 \\
\hline \multirow[t]{2}{*}{ S.S. } & Metastatic carcinoma of common bile duct & $4 / 20 / 65$ & & 14 & 17 & 20 & 22 & 22 & 20 \\
\hline & Postcholecystojejunostomy & $5 / 4 / 65$ & & 12 & 18 & 26 & 31 & 30 & 30 \\
\hline \multirow[t]{2}{*}{ A.S. } & Gall stone obstruction & $3 / 2 / 66$ & & 15 & 18 & 18 & 20 & 20 & 20 \\
\hline & Postcholecystectomy & $4 / 28 / 66$ & & 13 & 13 & 16 & 18 & 21 & 22 \\
\hline
\end{tabular}

was still slightly abnormal more than a month postoperatively.

Cirrhosis. Phenylalanine conversion tests in patients with cirrhosis were characterized by elevated fasting tyrosine levels and by delayed increases in plasma tyrosine levels (Fig. 2, Table II). The mean fasting level of $21.4 \mu \mathrm{g} / \mathrm{ml}$ was significantly higher than the mean level in normal subjects $(P<0.01)$. Increments in plasma tyrosine levels ranged from 2 to $25 \mu \mathrm{g} / \mathrm{ml}$ (mean, 8.1 ). In 13 cirrhotic patients peak increments in plasma tyrosine levels were less than $7 \mu \mathrm{g} / \mathrm{ml} .18$ of the 23 patients had abnormal phenylalanine conversion tests by virtue of either elevated fasting levels, flat curves, or both.

The mean peak percentage increase in plasma tyrosine concentration after phenylalanine administration was $157 \%$, clearly lower than in normal subjects. The peak tyrosine level achieved twice the fasting concentration in only 3 of the 23 cirrhotic patients. One patient with moderately severe cirrhosis who had an extremely low fasting tyrosine level $(5 \mu \mathrm{g} / \mathrm{ml})$ exhibited a six-fold increase after phenylalanine administration. The explanation for this low fasting tyrosine level, the lowest we have observed, is not known.

Peak tyrosine levels tended to occur later in cirrhotic patients than in normal subjects. Peak tyrosine levels were achieved within $2 \mathrm{hr}$ of the administration of phenylalanine in only eight patients. In four patients, peak values were insignificantly greater than fasting levels. In most of the remainder the peak occurred at $4 \mathrm{hr}$.

Cirrhotic patients with normal fasting tyrosine levels did not differ from those with increased levels either in clinical manifestations or by conventional liver function tests. However, there was a positive correlation between fasting tyrosine levels and the degree of abnormality of the ammonia tolerance test (Fig. 4). Similarly, abnormal phenylalanine conversion tests were found to correlate positively with abnormal ammonia tolerance tests (Fig. 5) but not with any other liver function test results or with any clinical manifestation of cirrhosis. Although patients in whom esophageal varices were seen esophagoscopically had higher mean fasting tyrosine levels and more frequently abnormal phenylalanine conversion tests

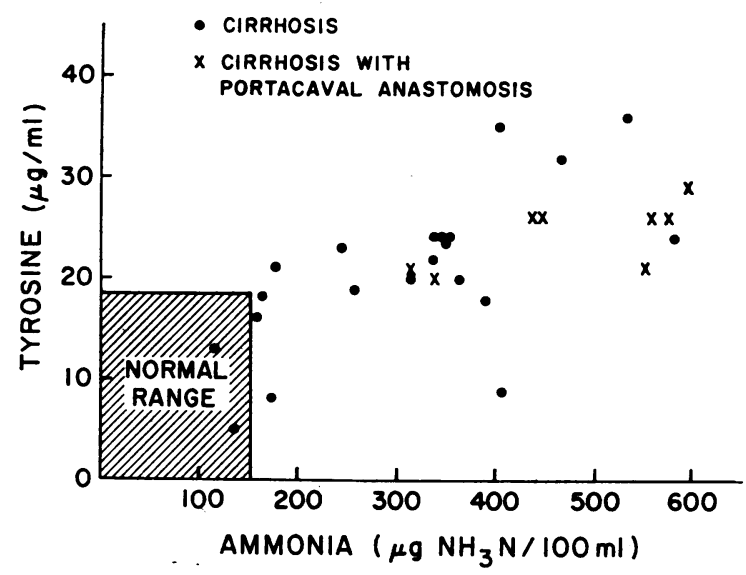

Fig. 4. Fasting Plasma tyrosine levels in patients WITH CIRRHOSIS PLOTTED AS A FUNCTION OF AMMONIA TOLERANCE. Patients with surgically constructed portacaval anastamoses are indicated. Ammonia tolerance is expressed as $\mu \mathrm{g}$ ammonia nitrogen per $100 \mathrm{ml}$ arterial blood $45 \mathrm{~min}$ after oral loading dose of $3 \mathrm{~g}$ of ammonium chloride. 


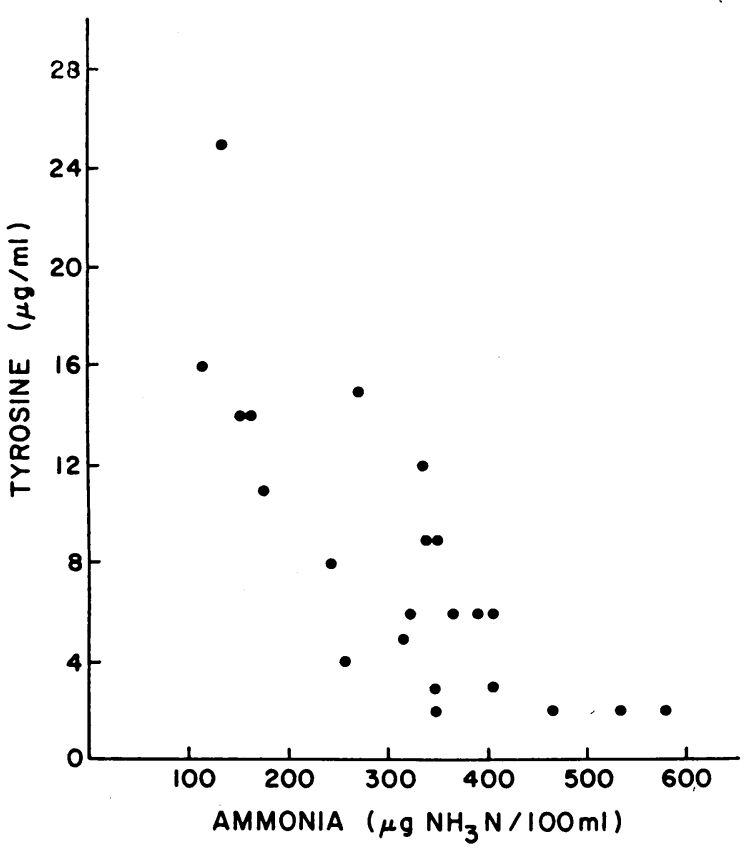

Fig. 5. MAXIMUM INCREMENT IN PLASMa tYROSINE LEVELS DURING PHENYLALANINE CONVERSION TESTS IN PATIENTS WITH CIRRHOSIS PLOTTED AS A FUNCTION OF $\mu \mathrm{g}$ AMMONIA NITROGEN PER $100 \mathrm{ml}$ ARTERIAL BLOOD 45 MIN AFTER AN ORAL LOADING DOSE OF $3 \mathrm{~g}$ OF AMMONIUM CHLORIDE.

than those in whom varices were not seen, the differences were statistically insignificant.

Phenylalanine conversion test curves in cirrhotic patients with portacaval anastomoses were very similar to those in cirrhotic patients without portacaval anastamoses (Table II). The results of

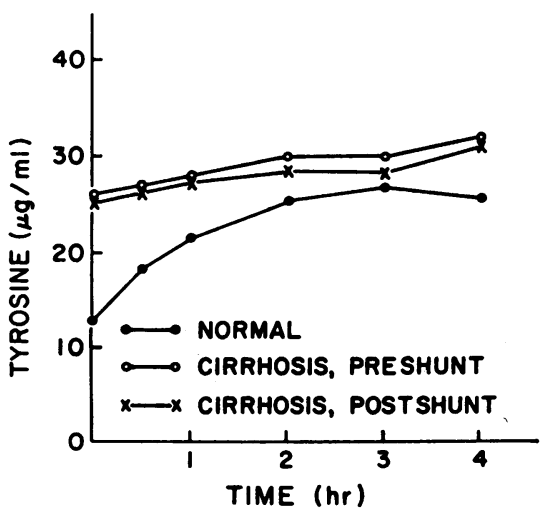

Fig. 6. Mean Phenylalanine CONVERSion test CURVES IN 10 NORMAL SUBJECTS AND IN 5 PATIENTS WITH LAENNEC'S CIRRHOSIS BEFORE AND AFTER SURGICAL CONSTRUCTION OF PORTACAVAL ANASTAMOSES. phenylalanine conversion tests before and after portacaval anastamoses in each of five patients were nearly identical (Fig. 6).

\section{Discussion}

These studies indicate that major disturbances exist in the metabolism of tyrosine in patients with liver disease. They confirm the findings of Bernhart and Schneider (3), that patients with liver disease tend to have high fasting levels of tyrosine in plasma and abnormal tyrosine tolerance tests, using a specific method for assay of tyrosine. In addition, they demonstrate impaired synthesis of tyrosine from phenylalanine in patients with hepatic disorders.

After phenylalanine loading the levels of tyrosine in plasma vary as a function not only of the rate of tyrosine. synthesis but also of the rate of its removal from plasma. Since, in patients' with liver disease, tyrosine is cleared from plasma at a subnormal rate, peak plasma tyrosine levels during phenylalanine conversion tests are probably higher than they would be if the rate of its synthesis were their sole determinant. Thus, comparison of peak increments in plasma tyrosine levels probably results in an underestimate of the magnitude of depression of phenylalanine hydroxylation. A better estimate of this depression is obtained by comparison of early increments in tyrosine levels after phenylalanine loading. Increments in plasma tyrosine levels during phenylalanine conversion tests in patients with liver disease were more strikingly subnormal during the $1 \mathrm{st} \mathrm{hr}$ than they were at their peaks. It should be noted, however, that both initial and peak increments in tyrosine levels were depressed significantly whether expressed as per cent increase or as absolute increase.

Two additional characteristics of the abnormal phenylalanine conversion test curves in patients with liver disease indicate an important contribution of impaired tyrosine clearance; viz., peak plasma tyrosine levels occurred later than they did in normal subjects and the beginning return toward fasting values generally was not observed as it was in normal subjects.

In patients with cirrhosis, the only clinical or laboratory manifestation of liver disease with which either abnormal phenylalanine conversion tests or high fasting tyrosine levels correlated posi- 
tively was the ammonia tolerance test. Ammonia tolerance tests, as performed in this laboratory (16), represent primarily a measure of portalsystemic collateral circulation (17-20). The results of ammonia tolerance tests rarely are abnormal in patients with either hepatitis or obstructive jaundice $(16,17,20)$, but usually are abnormal in cirrhotic patients with clinical signs of portal hypertension; e.g., ascites, splenomegaly, abdominal collateral veins, and esophageal varices (16, 18). In fact, the degree of ammonia intolerance in general reflects the magnitude of esophageal varices in patients with cirrhosis (21). In addition, ammonia tolerance tests are useful in determining the patency of surgically-constructed, portal-systemic anastomoses (22).

The correlation of impaired ammonia tolerance with abnormalities of tyrosine synthesis and catabolism and, particularly, the conversion of orally administered phenylalanine suggest that these abnormalities are due, in part, to shunting of blood from the portal to the systemic circulation and that these abnormalities may actually reflect lack of access to the liver. However, this cannot be the sole explanation for these abnormalities; portalsystemic shunting would not account for the abnormalities seen in patients with biliary obstruction or hepatitis. Furthermore, additional deterioration of phenylalanine conversion was not observed in cirrhotic patients after construction of portacaval anastamoses despite an increase in ammonia intolerance.

These findings support the belief that in man, as in rodents, synthesis and catabolism of tyrosine are accomplished largely in the liver. The observation that patients with major defects in both the synthesis and catabolism of tyrosine tend to have high fasting levels of tyrosine in plasma as well as in urine indicates that, in man, dietary sources of tyrosine are quantitatively more significant than synthesis.

Abnormal phenylalanine conversion tests were found in some patients with liver disease with minimal abnormalities in other liver function tests. More commonly, patients with substantial abnormalities in other liver function tests had little or no reduction in phenylalanine conversion. The phenylalanine conversion test did not distinguish between obstructive and other types of liver dis- ease, nor was it useful in differentiating hepatic parenchymal dysfunction from portal-systemic shunting. We must conclude that the phenylalanine conversion test offers no advantage of either specificity, sensitivity, or convenience over standard tests of liver function.

Finally, we wish to comment on the significance of these findings in the interpretation of clinical diagnostic tests based upon detection of abnormalities of tyrosine metabolism. Tyrosine tolerance tests done for the purpose of diagnosis of thyrotoxicosis and phenylalanine conversion tests done for the purpose of detection of heterozygous carriers of phenylketonuria may both yield falsely positive results in patients with hepatic disease. Tyrosinosis (hereditary p-hydroxyphenylpyruvic acid oxidase deficiency) is commonly complicated by cirrhosis (4); apparently, it is not generally appreciated that the abnormal tyrosine tolerance observed in these patients probably reflects not only a genetically determined enzyme deficiency but also the nonspecific effects of liver damage.

\section{Acknowledgments}

We acknowledge the expert technical assistance of Judy Johnson, Doris Watts, and Albert Kuljian.

\section{References}

1. Knox, W. E. 1955. Metabolism of phenylalanine and tyrosine. In A Symposium on Amino Acid Metabolism. W. D. McElroy and H. B. Glass, editors. John Hopkins Press, Baltimore. 836.

2. Frerichs, F. Th. 1854. Offenes Schreiben and den Herrn. Hofrath Dr. Oppolzer in Wien. Wien. Med. Wochshr. $4: 465$.

3. Bernhart, F. W., and R. W. Schneider. 1943. A new test of liver function-the tyrosine tolerance test. Am. J. Med. Sci. $205: 636$.

4. Efron, M. L. 1965. Aminoaciduria. New Engl. J. Med. 272 : 1058.

5. Levine, R. J., J. A. Oates, A. Vendsalu, and A. Sjoerdsma. 1962. Studies on the metabolism of aromatic amines in relation to altered thyroid function in man. J. Clin. Endocrinol. Metab. 22: 1242.

6. Rivlin, R. S., K. L. Melmon, and A. Sjoerdsma. 1965. An oral tyrosine tolerance test in thyrotoxicosis and myxedema. New Engl. J. Med. 272 : 1143.

7. Malamos, B., C. J. Miras, J. N. Karli-Samouilidou, and D. A. Koutras. 1966. The serum tyrosine level as an index of thyroid function. J. Endocrinol. $35: 223$. 
8. Kaufman, S. 1962. Aromatic hydroxylations. In Oxygenases. O. Hayaishi, editor. Academic Press, Inc., N. Y. 131.

9. Levine, R. J., W. Lovenberg, and A. Sjoerdsma. 1964. Hydroxylation of tryptophan and phenylalanine in neoplastic mast cells of the mouse. Biochem. Pharmacol. 13: 1283.

10. Knox, W. E. 1966. Phenylketonuria. In Metabolic Basis of Inherited Disease. J. B. Stanbury, J. B. Wyngaarden, and D. S. Fredrickson, editors. McGraw Hill Book Co., New York. 2nd edition. 258.

11. Hsia, D. Y. 1958. Phenylketonuria: the phenylalanine-tyrosine ratio in the detection of the heterozygous carrier. J. Mental Deficiency Res. 2 : 8.

12. Jervis, G. A. 1960. Detection of heterozygotes for phenylketonuria. Clin. Chim. Acta . 5: 471.

13. Levine, R. J., P. Z. Nirenberg, S. Udenfriend, and A. Sjoerdsma. 1964. Urinary excretion of phenethylamine and tyramine in normal subjects and heterozygous carriers of phenylketonuria. Life Sci. 3 : 651.

14. Goodfriend, T. L., and S. Kaufman. 1961. Phenylalanine metabolism and folic acid antagonists. $J$. Clin. Invest. $40: 1743$.
15. Waalkes, T. P., and S. Udenfriend. 1957. Fluorometric method for estimation of tyrosine in plasma and tissues. J. Lab. Clin. Med. 50: 733.

16. Conn, H. O. 1961. Ammonia tolerance as an index of portal-systemic collateral circulation in cirrhosis. Gastroenterology. 41 : 97.

17. Kirk, E. 19.36. Amino acid and ammonia metabolism in liver diseases. Acta Med. Scand. Suppl. 77: 1.

18. Conn, H. O. 1960. Ammonia tolerance in liver disease. J. Lab. Clin. Med. $55: 855$.

19. McDermott, W. V., Jr., and C. J. W. Huston. 1963. The oral ammonium tolerance test as aid in the investigation of suspected esophago-gastric varices. Ann. Surg. 158 : 820.

20. Stahl, J. 1963. Studies of the blood ammonia in liver disease; its diagnostic, prognostic, and therapeutic significance. Ann. Internal Med. 58: 1.

21. Conn, H. O. 1967. Ammonia tolerance in the diagnosis of esophageal varices. A comparison of endoscopic, radiologic and biochemical techniques. J. Lab. Clin. Med. 70: 442.

22. Eiseman, B., G. M. Lindeman, and G. M. Clark. 1956. Clinical evaluation of the ammonium citrate tolerance test for determining the patency of a portacaval shunt. J. Lab. Clin. Med. 48 : 579. 